\title{
Masculinidades, feminilidades e educação matemática: análise de gênero sob ótica discursiva de docentes matemáticos
}

Lucas Alves Lima Barbosa'

\section{Resumo}

0 questionamento central que se constitui como um disparador para as discussões aqui realizadas é: existem relações entre as concepções de gênero e o ensino da matemática? Diante da suposta evidência de que meninos possuem rendimento superior em matemática, o presente trabalho objetiva investigar as problematizações que podem ser feitas à educação matemática quando a relacionamos com questões de gênero, isto é, com as masculinidades, feminilidades e demais representações sociais que se alinham a essa perspectiva. E, também nesse sentido, pretende-se investigar quais os desdobramentos para o ensino da matemática quando determinadas concepções de gênero se encontram implícitas na prática docente. De fato, não é muito incomum depararmo-nos com afırmações do tipo "meninos têm mais facilidade para aprender matemática do que meninas" ou "a mulher é muito emotiva e pouco racional”, dentre outras, que podem trazer certas implicações para o ensino da matemática, como, por exemplo, a legitimação e a reafirmação de certas desigualdades já materializadas no âmbito social. No intuito de se problematizar tais afırmações que, de certa forma, podem acabar exercendo um papel fundamental na fixação de determinados binarismos concernentes às identidades de gênero, este trabalho apresenta uma discussão pós-estruturalista e investiga de que forma as relações de gênero estão presentes no ensino da matemática por meio da aplicação de entrevistas semiestruturadas com professores dessa disciplina.

\section{Palavras-chave}

Educação matemática - Gênero - Discursos - Práticas educativas.

I- Universidade Federal de Lavras, 


\section{Masculinities, femininities and mathematics education: gender analysis from the discursive view of mathematics teachers}

Lucas Alves Lima Barbosa'

I- Universidade Federal de Lavras,

Lavras, MG, Brasil.

Contato: lucaslima_62@hotmail.com

\begin{abstract}
The central question that triggers the discussions held here is: Are there links between gender conceptions and mathematics teaching? In the face of the supposed evidence that boys have superior performance in mathematics, this study aims to investigate possible problematizations of mathematics education when we relate it to gender issues, that is, masculinities, femininities, and other social representations aligned to this approach. It also investigates the consequences that certain conceptions of gender implicit in the teaching practice may have on mathematics teaching. Indeed, it is not uncommon to encounter statements such as "boys are better at mathematics than girls", or "women are very emotional and not rational enough", which can bring consequences to mathematics teaching, such as the legitimation and reaffirmation of certain inequalities already materialized in the social sphere. In order to challenge such claims that may somehow end up playing a key role in fixing certain binarisms of gender identities, this work presents a poststructuralist discussion and, by means of semi-structured interviews with mathematics teachers, investigates how gender relations are present in the teaching of this subject.
\end{abstract}

\section{Keywords}

Mathematics education - Gender - Discourses - Educational practices. 


\section{Introdução}

A educação matemática, vertente educacional que se debruça sobre questões relativas ao ensino/aprendizagem da disciplina de matemática, tem se caracterizado como foco de pesquisas científicas desde os primeiros anos da década de 70. Essa década, de acordo com Berti (2005), delineou um cenário favorável à ascensão de análises que passaram a problematizar os inflexíveis padrões com os quais se acreditava que o ensino de matemática deveria condizer.

No entanto, os reflexos das pesquisas em nossas salas de aula ainda são pouco visíveis. As políticas públicas têm se mostrado ineficazes na inserção de tais metodologias nos cenários práticos educacionais. Este fato é apontado nos Parâmetros Curriculares Nacionais (PCN) (BRASIL, 1998, p. 19), que deixam claro que "os movimentos de reorientação curricular ocorridos no Brasil, a partir dos anos 20, não tiveram força suficiente para mudar a prática docente dos professores para eliminar o caráter elitista desse ensino, bem como melhorar sua qualidade".

D’Ambrósio (1996, p. 31) constrói um pensamento nesse sentido ao dizer que "do ponto de vista de motivação contextualizada, a matemática que se ensina hoje nas escolas é morta". Diante disso, faz-se necessário que educadores matemáticos lancem mão de alternativas ideológicas que caminhem para uma aprendizagem matemática mais eficaz e abrangente. Algo que pode ser extremamente útil nesse processo é a problematização de temas relacionados ao gênero no interior da educação matemática.

Frente a isso, emergem como necessárias pesquisas que mesclem esses dois universos, o da educação matemática e o do gênero, a fim de se problematizar algumas concepções comuns na educação matemática, como a clássica afırmação de que homens são, naturalmente, melhores em matemática do que as mulheres, e buscar, em meio a essas intersecções entre questões de gênero e de educação matemática, subsídios para aprendizagens mais abrangentes e críticas.
São poucos os pesquisadores que têm se empenhado na busca por relações entre matemática e gênero. Souza e Fonseca (2010, p. 11) sublinham esta necessidade ao ponderarem que "discutir as relações entre gênero e matemática constitui, de certa forma, uma novidade no campo da Educação Matemática no Brasil". Buscando os não tão evidentes entrecortes entre gênero e educação matemática, é possível perceber que trabalhar no estabelecimento de tais relações não é algo apenas possível, mas também extremamente necessário.

\section{Da percepção do gênero como elemento socialmente construído à inclusão da matemática nesse contexto de construção}

De forma concisa, o gênero é tudo aquilo que, socialmente e culturalmente, nos define como sendo homens ou mulheres. Pertencer a um determinado gênero acrescenta aos nossos feitios uma série de modos de agir, de se vestir, de se comunicar, de trabalhar, de se divertir e de se praticar a sexualidade.

Faz-se necessário explicitar a vital distinção entre sexo e gênero. Grosso modo, o sexo é determinado anatomicamente: se nascemos com pênis, somos considerados do sexo masculino; se nascemos com vagina, somos considerados do sexo feminino. 0 gênero, por outro lado, é definido como sendo as características sociais atribuídas a um corpo sexuado. Tudo aquilo que culturalmente se atribui ao sujeito que possui vagina forma o gênero feminino e, analogamente, tudo aquilo que se atribui ao sujeito que possui pênis define o gênero masculino.

Em processos de construção do gênero nos sujeitos sexuados, mulheres e homens são chamadas e chamados a assumirem seus papéis, não nascem com esses papéis. As identidades de gênero são socialmente produzidas pelos discursos com os quais nos deparamos ao longo de toda a vida. Vejamos, pois, um exemplo: ao contrário do que muitos pensam, mulheres não 
nascem propensas a cuidar melhor de crianças do que os homens, nem a cozinhar, nem a cuidar da casa. Como afirma Louro (2003), são as sociedades que realizam esses processos de refinamento das habilidades de acordo com as exigências culturais. Tudo é uma questão de ajustamento, acomodação, encaixe, e não de natureza.

Existem dois fenômenos que nos ajudam a compreender melhor os instrumentos responsáveis por inscrever gêneros, comportamentos e atitudes em corpos sexuados: discursos e performatividade. Tomemos, primeiramente, o conceito de discurso. Para Foucault (1995, p. 55-56), os discursos são ferramentas que:

[...] formam sistematicamente os objetos de que falam. Certamente os discursos são feitos de signos; mas o que fazem é mais que utilizar esses signos para designar coisas. É esse mais que os torna irredutíveis à língua e ao ato da fala. É esse mais que é preciso fazer aparecer e que é preciso descrever.

Esse mais a que o autor se refere tem a ver com a capacidade dos discursos de, para além de apenas assinalar coisas, estruturar o pensamento do ouvinte com relação a essas coisas. E isto acontece de forma inconsciente. Deparamo-nos com enunciações e, como, para Foucault (2000, p. 20), somos seres de linguagem, essas linguagens nos preenchem e formam nossas estruturas interpretativas de pensamento, isto é, nosso modo de pensar.

Um conceito semelhante à noção de discurso é a ideia de performatividade desenvolvida, segundo Silva (2000), por Austin (1998) e por Butler (1999). Fundamentando nestas referências, Silva (2000) considera que, para entender a performatividade, é necessário fazer uma distinção entre dois tipos de enunciados: os descritivos e os performativos. Os enunciados descritivos são aqueles que descrevem determinada situação, como, por exemplo: "O livro está sobre a mesa". Os enunciados performativos, por outro lado, não se limitam a descrever um estado de coisas, mas contribuem para fazer com que algo realmente aconteça, como, por exemplo, "Eu vos declaro marido e mulher". São proposições cuja enunciação em si é necessária para que aquilo que ela descreve se torne realidade, isto é, proposições que criam fatos. No entanto, discursos aparentemente descritivos podem funcionar como performativos, na medida em que são repetidamente ditos. Um exemplo disso é a enunciação: "João é burro". Essa sentença, mesmo parecendo ser puramente descritiva, funciona como performativa, pois, repetida uma série de vezes, acaba por criar um fato: a burrice de João se torna real, graças à incisiva reprodução da frase que o define como ser não dotado de inteligência. É exatamente como se diz no interessante ditado popular inicialmente mencionado pelo nazista Paul Joseph Goebbels: "Uma mentira contada mil vezes torna-se verdade”. A performatividade dos enunciados está claramente presente na formação das identidades de gênero.

Mas, afınal, onde entra a matemática nessa história toda? Pois bem. Para compreender essa relação é necessário perceber que afirmações como "mulher não foi feita pra saber matemática" ou "mulher é muito emotiva e pouco racional”, coisas não dificilmente ouvidas ao nosso redor, podem funcionar dentro da lógica da performatividade para criar o fato de que realmente as mulheres inserem-se em um processo mais lento quando o que está em pauta é matemática.

Como apontam Almeida e Moura (2013, p. 4), “a constituição das subjetividades se dá através dos diferentes lugares por onde o sujeito transita, pelas diversas práticas sociais das quais participa”. Se nós nos constituímos, em relação a tudo que nos cerca, através das experiências e discursos que interferem diretamente no modo como avaliamos e interpretamos o mundo ao nosso redor, certamente também cultivamos nossa relação com a matemática permeados por tais estruturas discursivas que nos determinam.

Existe em nosso entorno uma produção histórico-discursiva que nos diz que "os homens são melhores em Matemática do que as mulheres”. Muitas vezes, não enxergamos nas práticas 
sociais com as quais nos envolvemos marcas explícitas dessa concepção, o que a torna quase invisivel, a ponto de até negarmos e duvidarmos de sua existência. No entanto, ela existe.

Carvalho (2004) nos mostra que concepções que minimizam as mulheres em todos os campos da vida social persistem ao nosso redor. Se elas persistem, certamente existem alguns esforços sociais que buscam mantê-las, que são os discursos. No campo da aprendizagem matemática, os mencionados esforços também marcam presença. Ressoando e repercutindo ao longo dos séculos, chegam até nós produções discursivas que reafirmam, dia após dia, que os meninos são, naturalmente, melhores em matemática do que as meninas.

E são esses mesmos discursos que utilizamos, ainda que de forma inconsciente e sem más intenções, em nossas salas de aula. Discursos que criam fatos e "verdades". Discursos que delimitam espaços a serem ocupados por homens e mulheres no espaço do desenvolvimento matemático, sendo próprio do homem desenvolver-se com muito mais facilidade e destreza do que a mulher. Pulverizadores de discursos que somos, nossos hábitos pessoais e métodos profissionais são sempre produtores de identidades de gênero, identidades que atribuem forçosamente a um corpo sexuado uma série de determinações socialmente "próprias" ao seu sexo. Mais uma vez, homens e mulheres são chamados a assumirem seus papéis. Segundo Souza e Fonseca (2009, p. 41-42):

Assim, em nossas salas de aula e naquilo que as compõe (gestos, palavras, silêncios, ritos, olhares, materiais, modos de organizar, modos de se ensinar matemática, concepções de aprendizagem, etc.) e em nossas pesquisas (mesmo quando se ocultam as relações de gênero), identidades masculinas e femininas são produzidas.

Santos e Cardoso (2012, p. 7-8, grifos nossos) realizaram um estudo empírico para compreender melhor de que forma as relações desiguais entre meninos, meninas e matemática se reproduzem discursivamente no interior da sala de aula de matemática:

Afirmamos, aqui, que essa desigualdade de gênero é naturalizada porque os sujeitos envolvidos nesse processo não observam que isso é construído por eles mesmos. Um exemplo de que isso acontece é quando a professora deu início à aula com uma atividade de decomposição de números. Em seguida, pediu para os alunos responderem no quadro e, como sempre, os meninos são chamados a participarem mais que as meninas (Diário de Campo, 23/02/2012). Nas observações feitas na sala de aula, notamos que a professora direciona a aula de matemática para os meninos, chama para responder as atividades no quadro, faz situações de problemas envolvendo os nomes deles e eles gostam de participar das aulas. Isso está tão naturalizado que a professora não investe nas meninas nessas aulas. $\mathrm{Na}$ correção de uma atividade, a professora chamou os alunos/as para irem até o quadro por fila. Das cinco filas que existem na sala, ela chamou quatro meninos e uma menina, e a mesma não quis ir responder (Diário de Campo, 01/03/2012). Essa aluna não teve incentivo da professora para ir responder a questão. Quando as meninas não queriam responder ela não insistia, ficava por isso mesmo, solicitando um menino para responder. Ao solicitar mais os meninos e incentivá-los mais do que as meninas, a professora produz uma diferença.

No interior desta lógica, não é de se estranhar que as meninas realmente "aceitem" sua posição de não muito afeitas à complexidade dos números diante dos contextos e situações que as perpassam ao longo de toda a vida escolar. Como nos diz Larrosa (2002, p. 21), "as palavras fazem coisas conosco".

Se, como nos diz Almeida e Moura (2013, p. 2), “em relação à Matemática, o Program of 
International Student Assesment (PISA) de 2010 [...] nos apresenta um resultado inferior das meninas no tocante ao desempenho em matemática na grande maioria dos países participantes", podemos conjecturar que isso não tem a ver com a ideia de que mulheres constituem-se como seres em falta, mas sim com as fortes produções discursivo-midiáticas que, possivelmente, incutem forçadamente nas mentes femininas a noção de que não nasceram para as ciências exatas, o que vem gerando, desde a escolarização elementar, um desestímulo em relação ao estudo dessa disciplina, desestímulo este que pode vir a ser causador dos índices apontados pelos testes de aprendizagem.

De acordo com Walkerdine (1995), não é que as garotas se saem mal na disciplina de matemática. 0 fato é que a "verdade" do desenvolvimento infantil patologiza e define o seu desenvolvimento matemático de modo que ele, essencialmente, seja entendido como inferior. A dicotomia masculino/feminino com relação à matemática não é natural: ela é construída e possui muitos reflexos e desdobramentos, como será possível observar nas entrevistas a seguir.

\section{Capturando "verdades" em entrevistas com professores de matemática}

Como vimos, os sujeitos sexuados vão se constituindo de maneiras diferenciadas dentro do contexto da aprendizagem matemática, contexto este que abarca estruturas masculinizantes e feminilizantes. Para compreender melhor a veracidade e a extensão deste problema que se constitui na polaridade homens/mulheres na matemática, onde os homens, a princípio, saem com vantagem, foram realizadas entrevistas semiestruturadas com professores de matemática da rede pública de ensino do município de Inconfidentes, sul de Minas Gerais, aferindo suas concepções e pensamentos com relação à questão do gênero submergida no ensino da matemática. Agora interessa-nos conhecer um pouco mais sobre as formas através das quais essa diferenciação se faz presente nos modos de pensar dos professores que diariamente a emanam, mesmo que indiretamente, discursos em suas salas de aula que certamente podem atuar fixando determinadas posições de sujeito.

A entrevista como ferramenta de análise do campo da educação matemática é compreendida aqui, de acordo com Fiorentini e Lorenzato (2006, p. 120), como sendo "uma conversa a dois com propósitos bem definidos”. Dentro dessa perspectiva, foram entrevistados cinco professores de matemática que terão aqui os nomes alterados a fim de preservar suas identidades. São eles: Karina, Caio, Mônica, Priscila e Simone.

\section{Os meninos saem na frente: algo} que persiste

É possivel identificar nas falas dos professores, antes de mais nada, certo consenso com relação à evidência de que, de fato, os meninos tem um desempenho em matemática superior se comparado ao desempenho das meninas. A professora Mônica, questionada nesse sentido, responde: "São. Ao longo dos anos que eu tenho de experiência, eu pude observar que os meninos têm mais facilidade pelo dia a dia deles". A resposta da professora apresenta-se de uma forma muito categórica e precisa, deixando claro que não existem dúvidas com relação ao que ela fala.

A professora Simone vai um pouco além, exemplificando esta evidente polaridade ao responder:

Quando chega no ensino médio, onde eu acho isso mais forte, os meninos começam a se preocupar mais com a faculdade, os meninos querem saber mais do estudo, se eu dou uma atividade, eles preocupam mais em fazer, ou se é um problema, quando eu questiono, os meninos respondem na frente, não que as meninas não vão bem, mas eu percebo que os meninos se sobressaem.

"Os meninos se sobressaem." Essa frase proferida pela professora não deixa dúvidas com relação ao que ela observa em sala de 
aula. 0 professor Caio, ao confrontar-se com a questão, diz que: "Os meninos, realmente, não só em uma ou duas salas, mas, no geral, eles estão levando vantagem”. Já a professora Karina quantifica sua resposta para ilustrar melhor a situação e responde: "Falando por quantidade, eu vejo que a maioria dos meninos, quer dizer, numa sala com trinta alunos, eu vou ter duas meninas que aprendem matemática muito mais fácil, e cinco meninos ou seis que aprendem mais rápido que essas meninas".

A professora Priscila introduz a variável do prosseguimento dos estudos na questão, ao responder: "Eu acho que os meninos têm muito mais aproveitamento. E até em questão de continuidade de estudos, se eu pegar uma turma que eu lecionei aí no fundamental ou médio, eu vejo que os meninos, a maioria deles, seguiram. As meninas nem tanto".

Todas as enunciações dos professores, mesmo que de maneiras diferentes, evidenciam o fato de os meninos estarem em vantagem na matemática. E é claro que estão mesmo. Não poderia ser diferente em uma sociedade que, historicamente, secundariza o feminino e suas especificidades, em que meninas crescem sendo desestimuladas, direta e indiretamente, no contexto do desenvolvimento matemático, fato detalhadamente mostrado e exemplificado por Santos e Cardoso (2012). A questão que se coloca como pertinente é buscar o porquê desta diferenciação, no intuito de problematizar a "evidente" diferenciação. E é exatamente isto que foi feito nas entrevistas, ou seja, buscar justificativas para verificar à que aspectos os professores associam a "evidência" do maior aproveitamento masculino no estudo da matemática. Para isso foi perguntando aos professores o porquê de os meninos irem melhor. Em geral, os porquês giram em torno de três eixos: 1) o comportamento feminino, diferente do masculino; 2) as atividades desenvolvidas pelos meninos no cotidiano, também diferente das atividades das meninas; 3) a naturalização, isto é, eles são melhores porque simplesmente são melhores. Vejamos como se configuram esses três porquês externados pelos professores individualmente.
O primeiro porquê: o comportamento feminino interferindo negativamente no estudo da matemática

Questionada com relação ao porquê de os meninos irem melhor na aprendizagem matemática, a professora Priscila diz que: "Dependendo da faixa etária, se pegarmos como exemplo na fase da adolescência, a gente vê diferenças, porque os meninos vêm pra sala de aula focados. Eles param de pensar em qualquer outra coisa, seja no futebol, seja numa festa, e se concentram”. Questionado também com relação ao porquê das diferenças, o professor Caio diz que:

É devido ao comportamento dos meninos e meninas em sala de aula. Então há uma diferença sim, que resulta em notas, que resulta na aprendizagem e tudo mais, porém mais relacionada ao comportamento da menina, não creio que devido à disciplina. As meninas se organizam melhor, elas controlam melhor o seu material didático, seu tempo didático, porém elas dispersam mais no quesito conversa. Então elas têm um caderno mais organizado, elas sabem o horário de fazer exercícios, de fazer tarefas, porém elas se perdem durante conversas, se distraem com isso. Os meninos eles não são tão organizados, você precisa delimitar o tempo pra eles, você não pode deixar eles escolherem o seu tempo pedagógico, você tem que vir delimitando, porém eles são funcionais. Quando o tempo é para exercício, eles não perdem, eles não se perdem.

As palavras do professor Caio associam o desenvolvimento inferior das meninas na matemática à "natureza" do comportamento feminino. A professora Simone também aponta para um tipo de comportamento:

Quando eu chego no $9^{\circ}$ ano, no Ensino Médio, eu percebo que a maioria dos alunos que estão na frente, que são mais atenciosos e que procuram aprender mais, são os meninos, e não as meninas. As meninas, 
parece que nesse momento é aquele momento onde elas estão preocupadas com namoradinhos, com o amor, e esquecem do interesse pela escola.

Seria esse comportamento, de acordo com os professores, um comportamento disperso e avoado, não tão focado quanto o masculino. As meninas se distraem durante os exercícios e atividades escolares, perdendo tempo com conversas, enquanto os meninos estão empenhados na resolução de certo exercício de maneira bastante funcional.

Sendo as garotas mais dispersas, certamente existem coisas que acontecem ao seu redor que chamam mais atenção do que a aula de matemática. Nesse sentido, a professora Priscila diz:

Eu acho que elas têm outras prioridades. 0 estudo não está na primeira lista delas. Elas têm outras prioridades. Para elas, talvez, estar com o cabelo penteado seja mais importante do que entender uma matéria de matemática. E os meninos são mais interessados, e eles conseguem se desligar. Eles podem até ter outros interesses, que para eles são importantes. Mas, a partir do momento em que eles entram, eles conseguem se desligar.

É necessário compreender, dentro de uma lógica crítica e atenta às produções sociais, a natureza característica de enunciações desse tipo, enunciações discursivamente constituídas e, ao mesmo tempo, constituidoras de verdades. Em outro momento da entrevista, ainda conversando sobre o comportamento feminino, a mesma professora diz também:

Na maioria das vezes, a gente nota que a vaidade fala mais alto, a outra colega, ah, eu quero ser melhor que a outra colega, ou elas estão mais interessadas no que acontece lá fora, então existe, sim, uma diferença grande. Eu noto que elas não têm muito foco. São muito mais dispersas.
Para elas, talvez, estar com o cabelo penteado seja mais importante do que entender uma matéria de matemática. A vaidade fala mais alto. 0 que está acontecendo por trás de tais enunciações é a imposição do gênero feminino, com todos os incontáveis valores simbólicos que ele agrega, sobre os indivíduos portadores de um sexo, no caso o sexo feminino. São os corpos sexuados vestindo-se de feminilidades para se enquadrarem e poderem dizer-se mulheres plenas, que se cuidam, se penteiam e se apresentam da maneira socialmente normatizada.

Isso está diretamente relacionado com parte da definição de Scott (1995) concernente ao gênero. Ao defini-lo, a autora sublinha com ênfase a questão dos símbolos e das representações simbólicas que se constituem como espelhos para que os indivíduos, dentro de limites muito bem especificados, moldem-se de acordo com a simbologia socialmente e culturalmente associada ao seu sexo.

Os símbolos, não ocasionalmente, oferecem a pauta para que o indivíduo possa se relacionar e se construir enquanto homem ou mulher. Dentro deste contexto de símbolos, nossa cultura supõe e até exige que as mulheres estejam sempre apresentáveis, bonitas e bem vestidas, ao contrário dos homens que são constituídos por outros símbolos, como o da virilidade, da força e da frieza frente aos sentimentos. E são a essas referências simbólicas do feminino, construídas e reiteradas em nossa sociedade, que os professores associam, em partes, a dita inferioridade das garotas no desenvolvimento matemático. As meninas constituem-se subjetivamente de acordo com as normatizações relacionadas ao gênero, e os professores, seres sociais igualmente dotados de verdades culturais, reproduzem esses padrões. Ao assumirem plenamente a feminilidade que lhes é acreditada, ao adotarem determinando comportamento social, as jovens meninas-mulheres têm uma série de coisas a fazer, o que tira o foco da aprendizagem matemática diante da constante necessidade de estar maquiada, estar penteada, estar depilada, estar cheirosa, estar magra e estar esbelta. Coisas que devem ser feitas para que a sociedade e os modos interpretativos 
presentes nesta sociedade as julguem e as entendam como pertencentes ao gênero feminino. Essa é, de fato, uma justificativa válida e que faz muito sentido, pois não é uma opção para as meninas enquadrarem-se ou não no gênero feminino com tudo aquilo que ele carrega consigo, mas sim uma imposição, gradativa e lenta, mas mesmo assim uma imposição.

\section{O segundo porquê: atividades do dia a dia masculino favorecendo a aprendizagem matemática}

Este porquê foi particularmente enunciado pela professora Mônica e diz respeito às atividades desenvolvidas pelos meninos no cotidiano, atividades que supostamente favorecem uma aprendizagem matemática mais eficaz. A professora Mônica diz que:

Ao longo dos anos que eu tenho de experiência, eu pude observar que os meninos têm mais facilidade pelo dia a dia deles. Se você pegar os números inteiros, por causa dos jogos, das tabelas, que é uma coisa que eles gostam, eles têm, dependendo do conteúdo, mais facilidade.

A professora associa diretamente 0 avanço masculino nas ciências exatas aos jogos e brincadeiras que fazem parte do dia a dia dos meninos, isto é, ao contexto vivenciado pelos garotos nos ambientes informais. É como se eles já chegassem na escola com um raciocínio mais amadurecido, ao contrário das meninas, justamente por conta desses jogos que acabam por desenvolver positivamente suas estruturas de pensamento. É como se o cotidiano dos garotos favorecesse a razão, e o feminino não.

Atentemo-nos, pois, para o que diz Souza e Fonseca (2010, p. 13) sobre esse processo de justificação baseado nos afazeres sociais. Segundo elas, "é preciso evitar, ainda, uma outra armadilha: a de se analisar diferenças entre resultados de mulheres e homens em matemática vinculando-as aos 'papéis' desempenhados por mulheres e homens na vida social".
A professora Mônica faz exatamente a vinculação problematizada pelas autoras, que caracterizam como sendo uma armadilha esse tipo de justificação. Isso porque essa simples associação pode nos impedir de olhar a questão com olhos mais apurados, levando em conta fatores mais abrangentes, como a construção social dos gêneros. Pode nos impedir também de visualizar de que forma essa diferenciação não simplesmente existe, mas sim persiste. Sendo assim, não podemos entender que é por conta das brincadeiras masculinas que os meninos saem na frente, pois, de fato, assim ficamos parcialmente impossibilitados de analisar a questão com o devido senso crítico que ela demanda.

\section{O terceiro porquê: naturalização}

A ideia da naturalização é o porquê que mais coopera para a legitimação de que a diferença entre homens e mulheres no desenvolvimento matemático é natural, normal e cristalizada. Vejamos um trecho da entrevista com a professora Karina:

Karina: - 0 caso dos meninos, eu acho mesmo que deve ser por eles conseguirem aprender mais rápido. Então você explicou uma vez, ele entendeu e não quer saber mais. Ele já quer fazer o processo de desenvolvimento, desenvolver o que eles já sabem.

Pesquisador: - Então eles vão além no sentido de raciocinar mais rápido?

Karina: - Isso.

Pesquisador: - Você ensaiaria algum porquê para a existência desse avanço deles no raciocinar mais rápido?

Karina: - Olha, eu não sei se é do fato de serem do sexo masculino, mas eu tenho a impressão que é essa necessidade que os meninos têm de resolver a coisa mais rápido para ficar livre mais rápido, o que acaba fazendo com que eles aprendam mais rápido. Porque 
as meninas são mesmo mais lentas, são mais preguiçosas, então os meninos têm aquela coisa: Eu quero fazer rápido para eu deixar de fazer. Quanto mais rápido eu faço, menos tempo eu vou precisar fazer. E as meninas não, elas estão em um processo mais lento.

Pesquisador: - Você acha que isso pode ser da própria natureza?

Karina: - Sim, da própria natureza.

A professora atribui as diferenças no desenvolvimento a certa natureza, uma natureza do feminino e uma natureza do masculino. De acordo com ela, os meninos são dotados de uma natureza mais imediatista, uma natureza da razão que anseia fazer tudo o mais rápido possível para dar seguimento ao processo de desenvolvimento da aprendizagem. Por outro lado, a professora também atribui uma natureza às meninas, uma natureza vagarosa e preguiçosa que faz com que elas estejam sempre imersas em um processo bem mais lento.

Quando fazemos enunciações do tipo "meninos são, naturalmente, melhores em matemática”, estamos, dentro da lógica foucaultiana, instituindo uma verdade para o ouvinte. Os signos que dão sustentação à frase não servem apenas para designar os elementos. Para além dessa funcionalidade básica, eles são extremamente úteis para criar consciências com relação ao sentido que a frase propõe. Como já sabemos, as consciências, para Michel Foucault, são sempre fabricadas na pluralidade dos discursos que nos constituem.

Quando fazemos esse tipo de enunciação, na verdade, contribuímos consideravelmente para estagnar qualquer possibilidade de transgressão por parte das meninas, já que muito dificilmente alguém consegue desviar de sua própria natureza. A natureza configura-se como um fio condutor de toda a existência feminina, e, sendo essa natureza menos veloz, os indivíduos que a possuem estarão sempre em um patamar inferior. Essa naturalização só serve para reforçar as posições binárias e intransmutáveis do masculino e do feminino dentro da aprendizagem matemática.
A professora Simone também trabalha com a ideia da naturalização das diferenças de uma forma muito explícita. Ela nos diz, considerando também sua experiência como professora na pré-escola:

E eu posso afirmar que já na matemática do jardim de infância, os meninos, eles raciocinam mais. No jardim também. As meninas são mais calculistas, para elas determinarem alguma coisa, elas têm que pensar mais, têm que mostrar para elas. Têm que ir mais para o lado visual, elas têm que ver. Os meninos já vão mais pelo raciocínio.

Para essa professora, os meninos vão melhor em matemática porque eles, simplesmente, raciocinam mais. Essa justificativa também se configura como uma naturalização das diferenças, pois é um estilo de pensamento que concebe esse maior desenvolvimento masculino como algo dado. Eles simplesmente raciocinam mais, e ponto final. É como se a natureza conspirasse a favor dos homens, conferindo a eles uma maior capacidade racional e intelectiva. De acordo com Silva (2000, p. 73):

Na perspectiva da diversidade, a diferença e a identidade tendem a ser naturalizadas, cristalizadas, essencializadas. São tomadas como dados ou fatos da vida social diante dos quais se deve tomar posição. Em geral, a posição socialmente aceita e pedagogicamente recomendada é de respeito e tolerância para com a diversidade e a diferença. [...] Essa perspectiva é suficiente para servir de base para uma pedagogia crítica e questionadora?

Sem sombra de dúvidas, não. Isso porque, quando naturalizamos, paramos imediatamente de questionar e de problematizar. Cristalizamos como verdade absoluta o fato de que os homens estarão sempre mais aptos para a matemática porque, naturalmente, raciocinam melhor, pensam melhor, mais rápido e de maneira mais eficaz. A naturalização das diferenças entre meninos e meninas, além de nos impedir de 
identificar as causas reais que levam meninos a se desenvolveram mais na matemática do que as meninas, não serve e nem pode vir a servir, em nenhuma hipótese, de base para uma pedagogia crítica e questionadora, realmente empenhada em conferir aos indivíduos, homens ou mulheres, emancipação intelectual.

Dentro da lógica de uma pedagogia crítica e questionadora, passamos a compreender como acontece a construção social dos gêneros no interior dos cenários de aprendizagem matemática. Em uma tentativa de caminhar rumo à desconstrução da falsa naturalidade das diferenciações, é necessário assumir de uma vez por todas que inexiste uma natureza masculina potencialmente mais evoluída ou, analogamente, uma natureza feminina inferiorizada.

\section{Cenários diferenciados para o desenvolvimento de meninos e meninas na aula de matemática}

É possivel captar nas entrevistas dos professores indícios de que em suas salas de aula acontecem situações, mesmo que não planejadas, que favorecem um maior desenvolvimento dos meninos. Bem, se as diferenças entre os meninos e as meninas na matemática não são dadas pela natureza, se meninos e meninas possuem as mesmas capacidades cognitivas para se desenvolverem igualmente, de onde surgem as diferenças? Como já foi mencionado anteriormente, existem esforços sociais, sutis e ao mesmo tempo arrebatadores, que constroem essas diferenças ao longo do desenvolvimento escolar das crianças. Tais esforços giram ao redor dos discursos que formam diferencialmente e sistematicamente os sujeitos sobre os quais versam. Muitos destes discursos são emanados pelos próprios professores de matemática, seres sociais que, mesmo dotados de uma formação acadêmica superior, trazem consigo, assim como todos nós, marcas e concepções naturalizantes e preconceituosas comumente encontradas no âmbito social.

Os professores de matemática, muitas vezes, mesmo que de forma absolutamente não intencional, acabam criando situações em suas aulas onde meninos se sentem mais à vontade para aprender, para questionar e para se desenvolver. Criam mais expectativas com os meninos, esperam mais dos meninos, o que gera neles uma maior vontade de aprender. Questionada com relação ao fato da criação de mais expectativas em relação aos meninos do que com as meninas, a professora Karina responde:

Com certeza. Eu acho que sim. Não que eu deixe as meninas de lado, eu tento passar para elas essa mesma, tento mostrar para elas que tanto a quantidade de meninos que estão se interessando, que estão aprendendo mais rápido, que elas também podem chegar nesse nível. Mas acabo tento um pouquinho mais de expectativa nos meninos, de achar que, na metade do exercício que eu estou explicando, por exemplo, eles já estão sabendo o que tem que fazer no resto. Então, às vezes, nem sempre isso acontece. Elas, normalmente, precisam de uma explicação boa para estar desenvolvendo.

A professora Karina deixa claro que cria mais expectativas em relação aos meninos do que com as meninas. Espera mais dos meninos, confia mais neles. A professora também comenta que parte da criação dessa expectativa maior em relação aos meninos acontece no interior das reuniões e em conversas com outros professores, nas quais os meninos são sempre posicionados em um nível superior. Ela diz:

0 que geralmente acontece em conversas com professores é a gente citar alguns alunos, que no caso são meninos, que eles têm um raciocínio muito rápido em matemática. No segundo ano, tem um aluno que você explica o exercício, quando você está na metade do exercício, ele já sabe como resolve o resto. $\mathrm{Na}$ outra sala do primeiro ano, tem outro aluno assim. No sétimo ano que eu dou aula, tem outro aluno assim. Então são sempre alunos, e dificilmente são alunas que se destacam, que a gente fala assim: "Nossa, que raciocínio ela tem". Normalmente são sempre meninos. 
A professora Priscila também comenta sobre esse mesmo fato: "Na maioria das reuniões. Na maioria. Eles já vêm falando, a primeira fala, a gente pode notar que os meninos fizeram isso, ou aquilo".

É claro que, diante dessa situação, os professores, mesmo que involuntariamente, vão sempre esperar mais dos meninos, e estimulá-los com maior afınco diante do seu "potencial mais apurado". Sobre essa questão das expectativas diferenciadas, o professor Caio também aponta para o mesmo sentido: "Sim. Com certeza. Todos os melhores alunos, as pessoas, assim, que eu percebo melhor os resultados, que eu fico com mais expectativa na hora de uma correção, na hora de propor um exercício, de fato, são os meninos”.

Desse modo, fica claro que os estímulos recebidos pelas meninas durante a aprendizagem matemática dessemelham-se dos estímulos recebidos pelos meninos. Dos meninos sempre se espera mais, conforme as expectativas criadas pelos professores. Isso fica explícito em suas falas. Não é de se estranhar que as meninas venham a se desenvolver menos vivenciando contextos dessa natureza, situações que envolvem expectativas não tão elevadas com relação a elas. Mais uma vez fica evidente que essa diferenciação não é natural, e sim construída.

\section{A família e suas preconcepções}

É claro que, se as meninas estão ficando para trás na aprendizagem matemática, conforme mostram inclusive algumas avaliações de larga escala que passaram a introduzir a variável sexo em suas análises, conforme apontam Corrêa, Sipraki e Soares (2012), os mencionados esforços sociais para manter a desigualdade não giram apenas ao redor dos contextos escolares. Como foi dito, esses esforços são sociais, e envolvem inclusive a família, que muitas vezes contribui para incutir gradualmente e forçosamente nas mentes das garotas que elas não estão para a matemática assim como os garotos.

Nas entrevistas, foi possível ter uma noção de como isso acontece. Foi perguntado aos professores se eles já vivenciaram alguma situação em diálogos com pais e/ou mães onde a defasagem das meninas ficou explícita. A professora Mônica afirma já ter ouvido isso muitas vezes, e exemplifica: "Isso já. Já ouvi sim de uma mãe de uma aluna que disse para mim que mulher não aprendia matemática. Que matemática era coisa de menino".

Isto nos leva a crer que a concepção de que meninos são, naturalmente, melhores em matemática, muitas vezes já vem de casa. 0 que acontece na escola é uma constante manutenção dessa concepção, que se configura como advinda inicialmente dos próprios contextos familiares. A professora Priscila, neste mesmo sentido, afırma que as meninas já chegam à escola com pensamentos deste tipo. Ela diz:

Muito. Já ouvi: “Ah, minha filha não aprende. Mas ela é menina, ela é burra mesmo". A própria família já passa isso para as adolescentes. Ao mesmo tempo que eles chegam trazendo na bagagem que a matemática é difícil, elas já vem pensando que matemática é difícil e eu não vou aprender porque quem aprende matemática é homem. Eu acredito que elas trazem isso sim.

Assim como todos nós, pais e mães possuem certas preconcepções muito cristalizadas e enraizadas. E é claro que acabam por passar isso para os filhos, seja em um gesto, em uma bronca, em um modo de olhar, ou em um diálogo.

A performatividade de Butler (1999) é uma ferramenta útil para compreendermos os efeitos subjetivos dessas enunciações familiares. 0 enunciado "Mas ela é menina, ela é burra mesmo", proferido por um pai, pode ser compreendido como um enunciado performático, pois, sendo oralmente repetível, possui a capacidade de fabricar o fato, fabricar a verdade de que meninas são burras. A inferioridade feminina se torna cada vez mais real na medida em que o enunciado vai sendo repetido. E as meninas, é claro, também capturam essa verdade e se constituem nos limites estabelecidos por ela, o que gera cerceamento de capacidades. No entanto, é em Gee (2008) que podemos encontrar uma explicação clara e precisa 
que confere sentido aos fenômenos observados pelos professores. De acordo com este autor, os discursos primários, isto é, aqueles assimilados por nós ainda no ambiente familiar e cultural de origem, relacionam-se com os discursos escolares, nomeados por ele como discursos secundários, de uma forma que resquícios das concepções primárias, por mais bem arquitetadas que sejam as secundárias, nunca desaparecerão por completo.

\section{Professoras de matemática e seus envolvimentos com as ciências exatas}

Outro ponto bastante interessante nas entrevistas foi quando as professoras foram questionadas com relação às suas experiências e vivências particulares com a matemática, principalmente no momento da formação acadêmica. Se existe certa estranheza social com relação ao envolvimento de mulheres na matemática, será que as professoras de matemática, diante do seu contato direto com este meio, chegaram a sentir, em algum momento, reflexos desta estranheza? No mesmo sentido, será que elas chegaram a vislumbrar marcas da construída supremacia masculina na matemática durante os anos em que estiveram na faculdade?

A professora Mônica comenta, relembrando seus tempos de faculdade: "Quando eu comecei, eles achavam que menino aprendia melhor matemática do que menina. Eu até falei para minha mãe: Então eu sou uma aberração da natureza, né? Porque sou mulher e gosto de matemática”. A concepção social de que mulheres não nascem para a matemática era tão sacralizada que, diante da sua vontade de partir para essa área, a professora chegou a pensar que poderia ser anormal.

As professoras comentam também sobre as dificuldades que tiveram durante o curso, destacando que essa dificuldade não se estendia aos homens. Karina diz que:

Eu via, dentro da própria sala de aula, vários meninos que se destacavam, muito mais do que a maioria das meninas que eram da turma. Porque a minha turma era meio mesclada, metade menina e metade menino. Mas sempre eram os meninos que acabavam se destacando. Daí, eu acabei me impondo que eu teria que aprender aquilo tanto quanto menino, não é porque ele seria um homem que eu não poderia chegar no mesmo patamar que ele. Então eu acabei me impondo isso de querer aprender a matemática. [...] Eu sempre via que a maioria eram os meninos que se destacavam mais, às vezes em um exercício mais complicado, eles entendiam mais rápido do que as meninas, isso eu vi. Mas eu acabei me impondo essa necessidade de estar chegando no mesmo patamar, independente do sexo.

A professora se impôs o encargo de chegar ao mesmo patamar em que supostamente os homens estavam. Se ela se propôs a alcançar este patamar, é claro que se compreendia em um nível inferior por ser mulher. Ela tinha em mente que teria que correr muito atrás, se dedicar muito, bem mais do que os meninos, para, de certa forma, desviar da sua natureza feminina pouco racional e pouco voltada para o estudo das ciências exatas, e obter êxito ao longo da graduação. A professora trazia claramente consigo a noção naturalizada de que as mulheres não são muito afeitas à matemática e ver os homens se destacando contribuía para a inquestionabilidade dessa noção.

A professora Simone diz que:

Quando eu fui fazer faculdade eu senti isso. [...] Quando eu fui para a faculdade, eu me senti perdida. E os amigos que me ajudavam nessa parte de álgebra, de geometria, eram os meninos. E, assim, eles já estavam empregados, e eu tive essa impressão que eles tinham uma aprendizagem melhor, absorviam mais forte essa parte da matemática do que eu. E muitas mulheres da minha turma também eram ajudadas por eles. [...] Na faculdade eu senti dificuldade, muita dificuldade de 
acompanhar a turma, onde os meninos eram melhores. Eu não me lembro de nenhum menino com dificuldade.

Fica claro que a professora chegou a vislumbrar marcas da construída supremacia masculina na matemática, pois precisou dos meninos, assim como outras colegas de faculdade, para auxiliá-la em momentos em que não conseguia acompanhar certos conteúdos.

Faz-se necessário ressaltar, com vistas a estudos e questionamentos futuros, a necessidade de estendermos este tipo de questionamento também aos homens, pois, de fato, não seria sensato, dentro do contexto teórico-prático no qual esta pesquisa se insere, considerarmos generalizadamente que eles são imunes a estranhamentos com relação ao ambiente acadêmico matemático.

\section{Consideraçōes finais}

0 objetivo do presente trabalho foi analisar como se configuram as diferenças entre meninos e meninas no contexto da aprendizagem matemática, utilizando e compreendendo os discursos, incluindo-se os dos professores, como construtores de verdades subjetivas. Nesses enlaces teóricos entre matemática e questões de gênero, buscou-se estudar e investigar como as relações e diferenciações relativas ao gênero estão presentes no âmbito da sala de aula de matemática. Temos como conclusão que essas diferenciações não apenas estão presentes, como também operam de um modo determinante para o andamento das atividades pedagógicas concernentes à matemática.

Como foi possível observar, essas diferenciações se fazem presentes nos momentos de aprendizagem matemática de um modo tão sutil que, muitas vezes, nem chegamos a percebê-las. Essa sutileza pode ser traduzida nas expectativas criadas pelos professores com relação ao desempenho matemático das meninas, que se configuram como sendo diferentes daquelas que os docentes nutrem com relação aos meninos, conforme pode ser constatado nas entrevistas realizadas e nos escritos de Santos e Cardoso (2012).

Diante da evidência estatística de que meninos têm um rendimento superior em matemática, como mostram Corrêa, Sipraki e Soares (2012), surgem diante de nossos olhos dois caminhos, um fácil e um difícil. 0 difícil nos convida a problematizar, e o fácil nos convida a naturalizar. Percorrendo o caminho fácil, o caminho da naturalização, associamos com tranquilidade as diferenças apontadas pelas avaliações estatísticas, nas quais os meninos saem na frente, a uma natureza racional do masculino que, justamente por ser mais racional, encaixa-se melhor com a matemática e tudo aquilo que ela exige. Este trabalho, no entanto, se aventurou e continua se aventurando pelo caminho difícil, não se contentando em simplesmente aceitar que existe uma natureza masculina mais preparada para acolher com conforto os elaborados raciocínios matemáticos, que permeiam a vida escolar de todos nós.

Percorrendo o caminho da não naturalização, somos convidados a problematizar e a duvidar, e foi o que o presente trabalho se propôs a fazer, ao questionar tudo o que diz respeito a essências inatas masculinas ou femininas, bem como universalidades intransmutáveis. Propomo-nos, desse modo, a realizar movimentações de desnaturalização de estruturas discursivas, impostas pelas relações de poder às quais estamos constantemente subjugados, tendo em vista que perspectivas naturalizadoras de diferenças intensificam as desigualdades que marginalizam os indivíduos.

Somos convidados, no percurso da não naturalização, a estranhar. Somos convidados a olhar as estatísticas que mostram os meninos saindo na frente com olhares mais apurados. Devemos nos questionar quais são os contextos e discursos que perpassam as vidas dessas meninas traduzidas em números pelas estatísticas.

Em meio aos movimentos de desnaturalização, buscou-se encontrar explicações para os resultados apontados pelas estatísticas sem, no entanto, associá-los à natureza. Procurando tais explicações foi possivel encontrar a questão da construção social dos gêneros que colocam 
sobre os homens e sobre as mulheres cargas e expectativas que traçam rotas e predeterminam espaços a serem ocupados por meninos e meninas em absolutamente todos os contextos, inclusive na aprendizagem matemática. E é justamente o processo de construção social dos gêneros o grande gerador da diferenciação. Meninos não são naturalmente melhores em matemática do que as meninas, eles se vestem compulsoriamente de um gênero, o masculino, que abarca uma infinidade de símbolos que atribuem a eles uma supremacia, histórica e coletivamente construída, nos espaços de desenvolvimento matemático. Analogamente, meninas não são naturalmente piores em matemática do que os meninos, elas se vestem compulsoriamente de um gênero, o feminino, que abarca uma infinidade de símbolos que atribuem a elas uma posição de inferioridade histórica e coletivamente construída nos espaços de desenvolvimento matemático.

Desmistificar a verdade de que meninos são naturalmente melhores em matemática é um desafio que se coloca à nossa frente.
Mesmo sendo algo extremamente difícil, devemos estar sempre atentos a processos desmistificadores da mencionada verdade, pois as implicações da adoção desses conceitos em salas de aula recairão sobre vidas que, de certa forma, serão norteadas pelos nossos discursos enquanto professores. Isso porque, como seres atravessados por linguagens - e pulverizadores de linguagens - somos produzidos por e produzimos identidades masculinas e femininas, que se prendem a pautas que impedem ou pelo menos dificultam inúmeras possibilidades de transcendência por parte dos indivíduos.

Por fim, seria a igualdade de gêneros, de fato, uma utopia? Se sim, não existe mal em ser. Assim como Galeano (2000, p. 102):

[...] acredito que ela [a utopia] está lá no horizonte. Me aproximo dois passos, ela se afasta dois passos. Caminho dez passos e o horizonte corre dez passos. Por mais que eu caminhe, jamais a alcançarei. Para que serve a utopia? Serve para isso: para que jamais deixemos de caminhar.

\section{Referências}

ALMEIDA, Marcia Furlan; MOURA, Anna Regina Lanner. Desconstrução: as relações de gênero e a educação matemática nos anos iniciais do ensino fundamental. In: ENCONTRO NACIONAL DE EDUCAÇÃO MATEMÁTICA, 11., 2013. Anais do... Curitiba: [s. n.], 2013.

\section{AUSTIN, John Langshaw. Como hacer cosas con palabras. Barcelona: Paidós, 1998.}

BERTI, Nívia Martins. 0 ensino de matemática no Brasil: buscando uma compreensão histórica. Ponta Grossa, [s. n.], 2005. Trabalho apresentado na "VI Jornada do HistedBr - História, Sociedade e Educação no Brasil". Universidade Estadual de Ponta Grosa - UEPG.

BRASIL, Ministério de Educação e do Desporto. Secretaria de Educação Fundamental. Parâmetros curriculares nacionais matemática: terceiro e quarto ciclos do ensino fundamental. Brasília, D̉F: MEC, 1998.

BUTLER, Judith. Corpos que pensam: sobre os limites discursivos do "sexo". In: LOURO, Guacira Lopes (Org.). 0 corpo educado: pedagogias da sexualidade. Belo Horizonte: Autêntica, 1999. p. 151-172.

CARVALHO, Maria Eulina Pessoa. Pierre Bourdieu sobre gênero e educação. Revista Ártemis, João Pessoa, v. 1, dez. 2004.

CORRÊA, Vanisse Simone Alves; SIPRAKI, Robson; SOARES, Maria Tereza Carneiro Soares. Uma análise de gênero: resultados matemáticos no PISA (Brasil e Argentina). Boletim da Sociedade Brasileira de Educação Comparada, Porto Alegre, 2012. Disponível em: <http://www.sbec.org.br/evt2012/trab54.pdf>. Acesso em: 30 set. 2014.

D’AMBRÓSIO, Ubiratan. Educação matemática: da teoria à prática. Campinas: Papirus, 1996.

FIORENTINI, Dario; LORENZATO, Sergio. Investigação em educação matemática: percursos teóricos e metodológicos. 3. ed. Campinas: Autores Associados, 2006.

FOUCAULT, Michel. A arqueologia do saber. Rio de Janeiro: Forense Universitária, 1995. 
FOUCAULT, Michel. As palavras e as coisas. 8. ed. São Paulo: Martins Fontes, 2000.

GALEANO, Eduardo. 0 livro dos abraços. 7. ed. Tradução de Eric Nepomuceno. Porto Alegre: L\&PM, 2000.

GEE, James Paul. Social linguistics and literacies: ideologiy in discourses. 3. ed. New York: Routledge, 2008.

LARROSA, Jorge. Notas sobre a experiência e o saber da experiência. Revista Brasileira de Educação, Rio de Janeiro, n. 19, p. 20-28, jan./abr. 2002.

LOURO, Guacira Lopes. Pedagogias da Sexualidade. In: LOURO, Guacira Lopes. (Org.). 0 corpo educado: pedagogias da sexualidade. 2. ed. Belo Horizonte: Autêntica, 2003.

SANTOS, Jailma; CARDOSO, Lívia de Rezende. Relações de gênero na educação matemática dos anos iniciais do ensino fundamental. In: COLÓQUIO INTERNACIONAL "EDUCAÇÃO E CONTEMPORANEIDADE", 6., São Cristóvão, 2012. Colóquio... São Cristóvão: [s. n.], 2012.

SCOTT, Joan Wallach. Gênero: uma categoria útil de análise histórica. Educação \& Realidade, Porto Alegre, v. 20, n. 2, p. 71-99, 1995.

SILVA, Tomaz Tadeu. A produção social da identidade e da diferença. In: SILVA, Tomaz Tadeu (Org.). Identidade e diferença: a perspectiva dos estudos culturais. Petrópolis: Vozes, 2000.

SOUZA, Maria Celeste Reis Fernandes; FONSECA, Maria da Conceição Ferreira Reis. Conceito de gênero e educação matemática. Bolema, Rio Claro, v. 22, n. 32, 2009.

SOUZA, Maria Celeste Reis Fernandes; FONSECA, Maria da Conceição Ferreira Reis. Relações de gênero, educação matemática e discurso: enunciados sobre mulheres, homens e matemática. Belo Horizonte: Autêntica, 2010.

WALKERDINE, Valerie. 0 raciocínio em tempos pós-modernos. Educação \& Realidade, Porto Alegre, v. 20, n. 2, jul/dez, 1995.

Recebido em: 07.05.2015

Aprovado em: 22.09.2015

Lucas Alves Lima Barbosa é licenciado em matemática pelo Instituto Federal de Educação, Ciência e Tecnologia do Sul de Minas Gerais. Foi bolsista de iniciação científica entre 2014 e 2015 e aluno de iniciação à docência entre 2011 e 2014. É mestrando em educação pela Universidade Federal de Lavras, Lavras, MG, Brasil e membro do grupo de pesquisa Fesex Relações entre filosofia e educação para a sexualidade na contemporaneidade: a problemática da formação docente. 